\title{
Alertas de tiempo severo mediante descargas eléctricas: el algoritmo del Lightning Jump en el Servei Meteorològic de Catalunya
}

https://doi.org/10.31978/639-19-010-0.023

\author{
Carme Farnell Barqué ${ }^{1}$ (carme.farnell@gencat.cat) \\ Tomeu Rigo Ribas ${ }^{1}$ (tomeu.rigo@gencat.cat)
}

${ }^{1}$ Servei Meteorològic de Catalunya (SMC)

\begin{abstract}
RESUMEN
El Servei Meteorològic de Catalunya (SMC) ha desarrollado una versión de la herramienta del Lightning Jump que, basada en datos totales de descargas eléctricas, permite realizar avisos de tiempo severo (granizo de diámetro superior a $2 \mathrm{~cm}$, vientos fuertes asociados a convección, tornados y/o reventones) con una antelación de entre 30 y 120 minutos. Este tiempo de antelación depende de la tipología de la tormenta, pero pretende ser un revulsivo a la hora de poder ayudar a Protección Civil a la hora de mejorar las alertas y, además, gestionar de manera más eficiente los equipos de emergencia, acotando las zonas a avisar. Después de un periodo inicial de análisis de episodios históricos (2006-2013), se puso en fase preoperativa la herramienta durante la campaña 2016. En la siguiente se analizó la casuística del tiempo real y, en la de 2018, se ha realizado un trabajo de gestión de la herramienta, con la realización de avisos a nivel interno. Las dos últimas campañas han permitido mejorar también la obtención de registros en superficie, hecho que ha facilitado la validación de la herramienta. Este último punto resulta clave a la hora de ayudar al predictor a entender el funcionamiento de la aplicación y cómo debe actuar en situaciones del tiempo real. Está previsto que durante la campaña 2019 ya se realicen avisos a nivel operativo.
\end{abstract}

PALABRAS CLAVE: Lightning Jump; relámpagos; tiempo severo; predicción; observaciones; avisos.

\section{INTRODUCCIÓN}

El tiempo severo afecta anualmente a Cataluña en numerosos episodios. Según el National Weather Service (NWS) de Estados Unidos, se entiende por tiempo severo: granizo superior a 2,5 cm, tornados o mangas, reventones y fuertes rachas de viento asociadas a tormentas (figura 1).

Teniendo en cuenta los distintos fenómenos asociados a tiempo severo, las granizadas son las más frecuentes y dañinas para la sociedad en Cataluña, sobre todo durante los meses estivales. A finales de primavera y principios de verano son las comarcas del interior del país las más afectadas por ese tipo de fenómenos, debido a las altas temperaturas diurnas que se registran durante ese periodo. En función de la situación sinóptica dominante, la zona más afectada puede ser el Pla de Lleida, el Prepirineu o el interior de las comarcas de Girona. Ver zonas en la figura 3. 

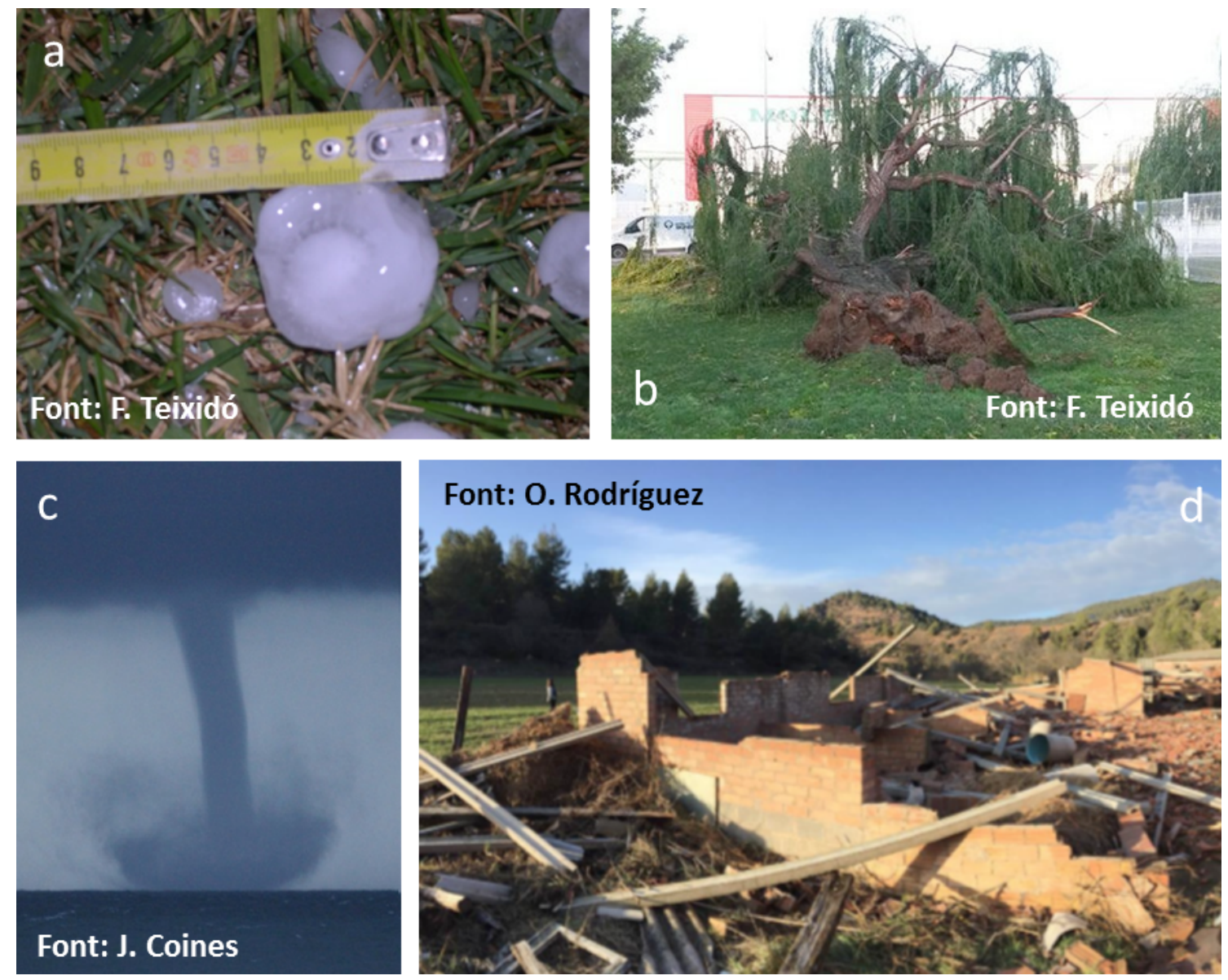

Figura 1. Fenómenos asociados con tiempo severo: a) Granizo; b) Reventón; c) Manga; d) Tornado.

En cambio, a finales de verano y principios de otoño son las zonas costeras las más afectadas, aunque con una menor frecuencia respecto al periodo anterior. Esto es debido a las elevadas temperaturas que almacena el mar Mediterráneo. Esa misma distribución se puede observar en la representación de las observaciones de granizo registradas durante el año 2016.

Figura 2.

Distribución mensual de las observaciones de granizo registradas durante el año 2016.

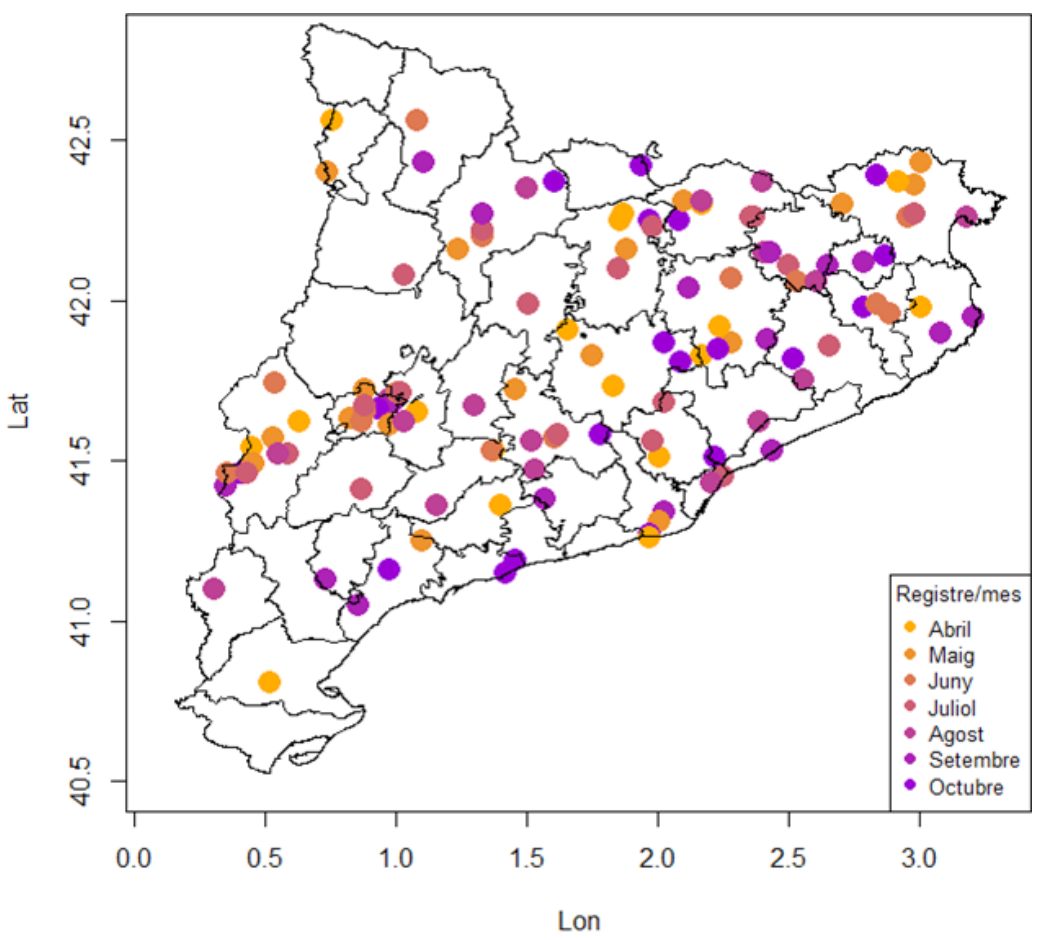




\section{ZONA DE ESTUDIO}

El estudio se ha centrado en Cataluña, área situada en el noreste de la península ibérica. Se caracteriza por ser un país con una elevada complejidad orográfica. Al norte se encuentran los Pirineos, con cotas de hasta 3100 m; moviéndose de sur-oeste a nordeste, se encuentra el sistema montañoso del Prelitoral con cotas de 1700 m, y muy cerca, el mar Mediterráneo. El área más interior es una zona llana con una cota que se mueve de los 200 a los $400 \mathrm{~m}$ y se enlaza con la depresión del Ebro. En esta misma área encontramos el Pla de Lleida.

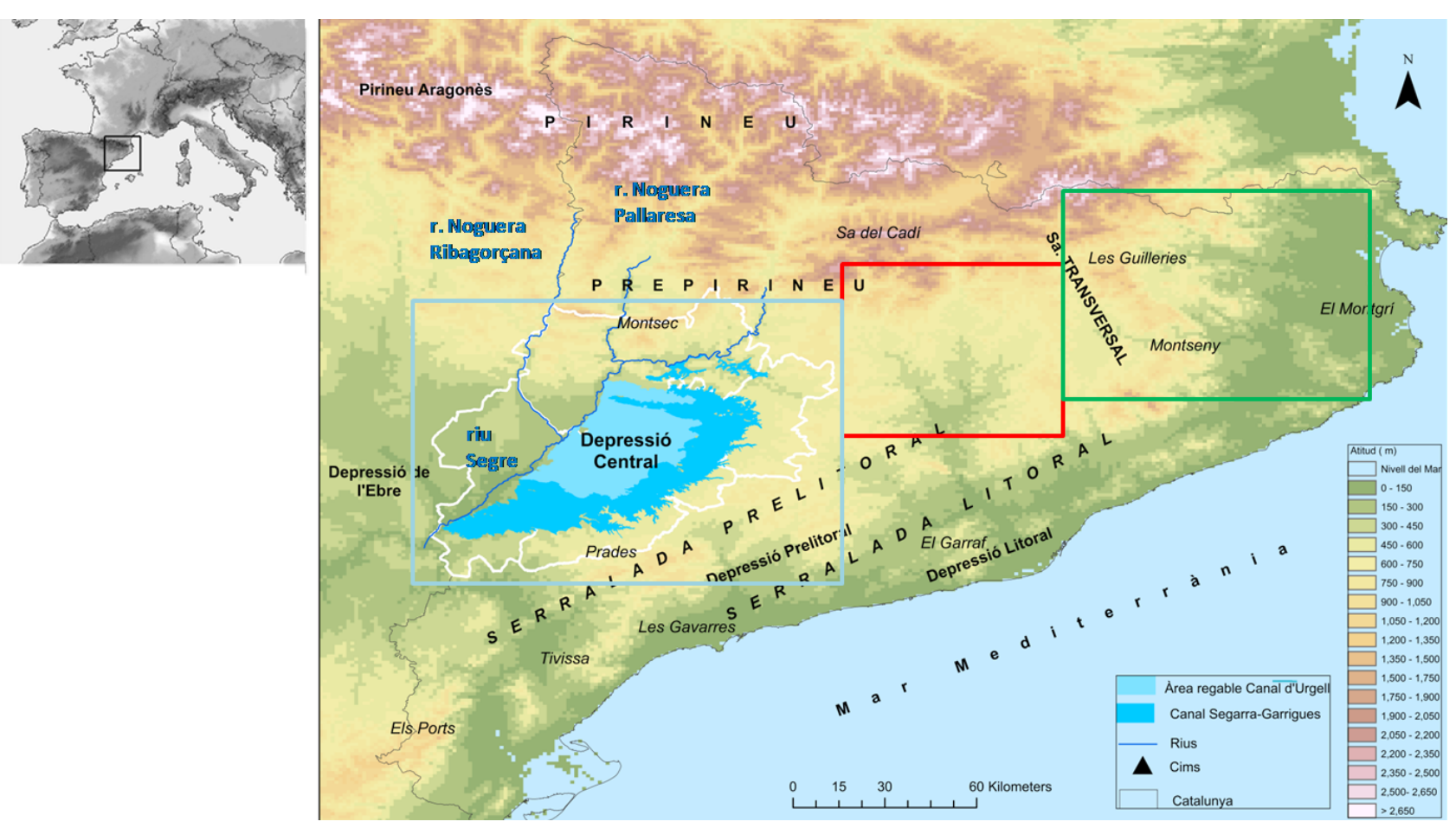

Figura 3. Área de estudio: Cataluña.

En azul: Pla de Lleida; en rojo: Cataluña central; en verde: interior de las comarcas de Girona.

\section{METODOLOGÍA Y RESULTADOS}

Con el fin de encontrar una herramienta óptima para el pronóstico del tiempo severo, se ha analizado el comportamiento del Lightning Jump (LJ), que es un fenómeno que se produce minutos antes de la presencia de tiempo severo. Se trata de un incremento súbito del número de descargas eléctricas (WiLliams, 1999), debido a la intensificación de la corriente ascendente dentro de la tormenta, la cual favorece el choque entre las partículas de hielo y, por tanto, una mayor separación de la carga (WILLIAMS, 2001).

Schultz et al. (2009) desarrollaron un algoritmo (de ahora en adelante, S09) para identificar este tipo de fenómeno. Posteriormente, Galtin y Goodman (2010), realizaron una variante del mismo. Este algoritmo trata de detectar incrementos abruptos en el número total de descargas (nube-nube, NN, más nube-tierra, NT) para identificar el fenómeno del LJ.

Desde el SMC se ha trabajado con el algoritmo S09, pero con importantes modificaciones y adaptaciones a la zona de estudio. La nueva versión, presentada en FARnell et al. (2017), la citaremos como F17. La primera variación es prescindir de las imágenes del radar para detectar estructuras. De este modo, trabajando únicamente con descargas eléctricas, se puede ejecutar el algoritmo minutalmente, y no cada 6 minutos como 
se haría en el caso que utilizáramos datos radar (en el caso del SMC, porque en el caso de AEMET sería cada10 minutos). Además, únicamente con las descargas se es capaz de localizar la parte más activa de la tormenta (figura 4). Esta figura presenta la selección de un núcleo tempestuoso con posibilidad de activar una alerta LJ. La figura 4a presenta el caso teniendo en cuenta la imagen de reflectividad del radar junto con las descargas eléctricas. Por el contrario, la figura $4 \mathrm{~b}$ muestra la misma tormenta detectada solo considerando las descargas eléctricas, que son representadas con puntos negros.
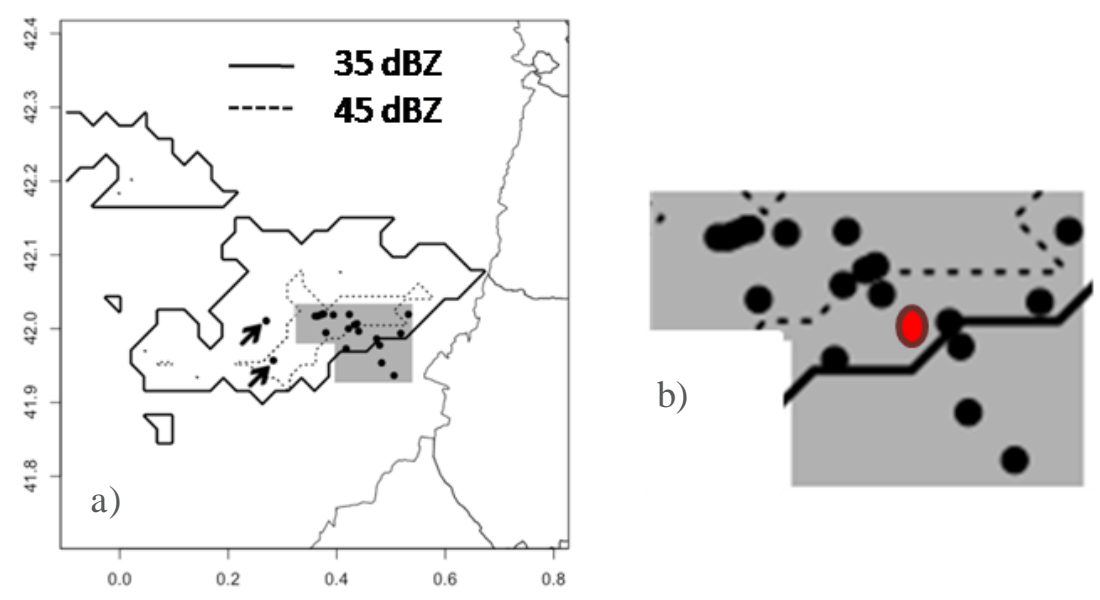

Figura 4.

a) Celdas rasterizadas a partir de los datos puntuales (descargas) a píxeles con una malla de $1 \times 1 \mathrm{~km}$. b) Localización del centroide del área que representará la zona a estudiar; punto rojo) centroide.

El procedimiento del LJ, F17, aplicado en el SMC consiste en:

1. Obtención de las descargas asociadas a cada uno de los núcleos tempestuosos en el instante actual (figura 4b).

2. Rasterización de los datos puntuales (relámpagos) a una matriz de $1 \mathrm{~km} \times 1 \mathrm{~km}$. Los píxeles continuos entre sí y con más de una descarga pasan a ser un área, cuyo centroide la identificará y caracterizará a partir de la hora, las coordenadas, el número de descargas y el tamaño del área.

3. Se observa la evolución del centroide en sus últimos 14 minutos. Esta debe cumplir con dos requisitos: continuidad espacial y temporal durante este periodo, con la finalidad de evitar rupturas de la propia estructura o bien células con un ciclo de vida inferior a este periodo de tiempo.

a)

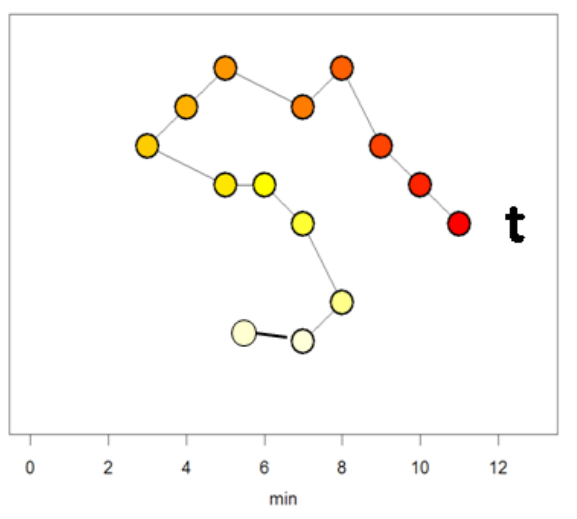

b)

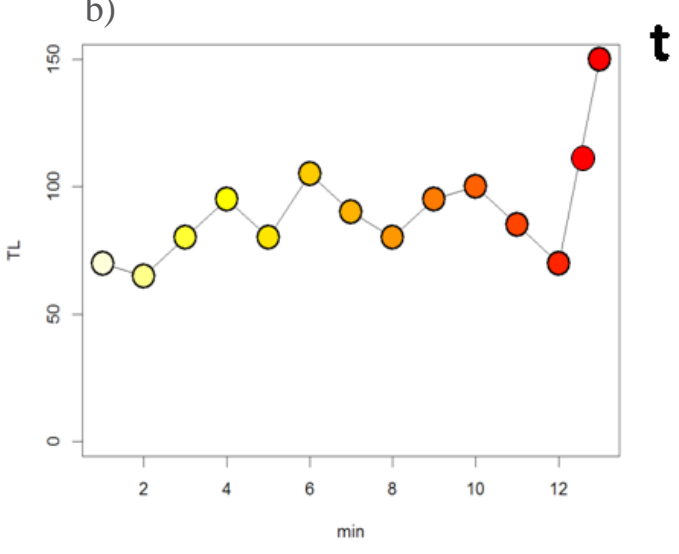

Figura 5. a) Evolución temporal y b) Evolución espacial durante los 14 minutos que tiene en cuenta el algoritmo.

4. Finalmente, se aplica la parte final del algoritmo original con el objetivo de encontrar un incremento súbito en el número de descargas, es decir, mirar si la variación en el último periodo excede el doble de la desviación estándar de todo el periodo previo. 


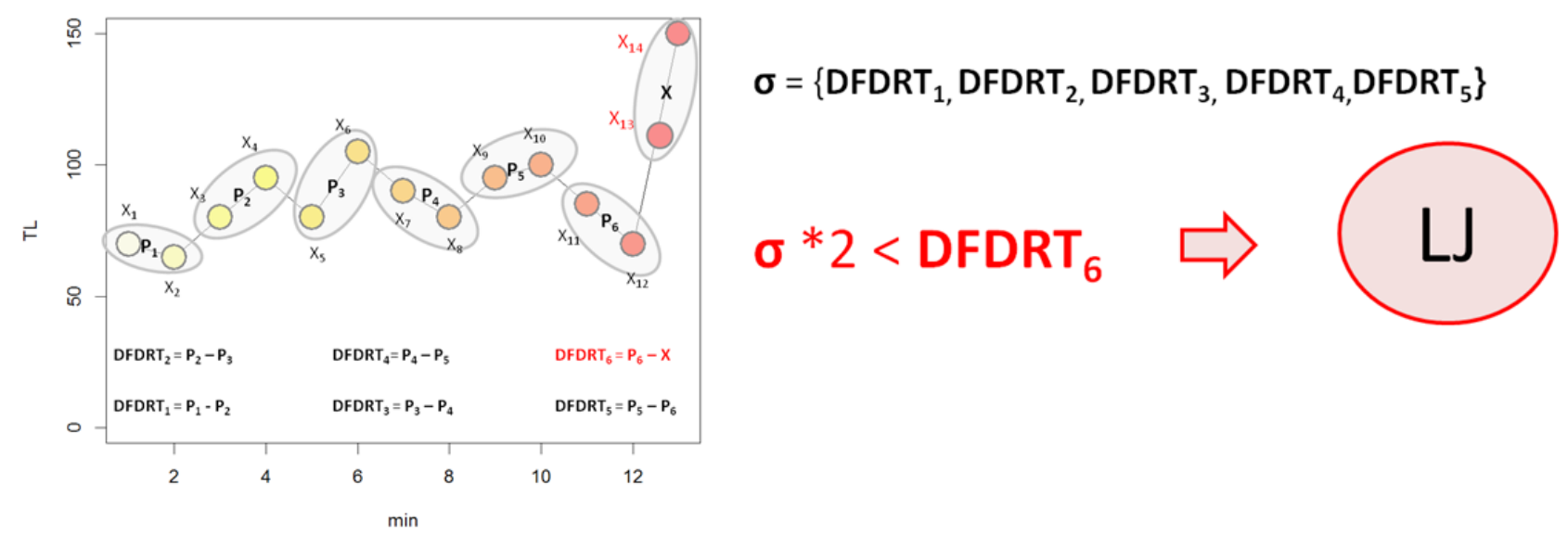

Figura 6. Punto final de la aplicación del algoritmo, en el cual se decide si hay un incremento súbito de la actividad eléctrica en el último minuto y, por lo tanto, se activa la alerta.

Es relevante la capacidad de detectar todo tipo de descargas, NN y NT, con una elevada eficiencia, ya que no todas la redes son capaces de hacerlo (figura 7). La Xarxa De Descàrregues Elèctriques (XDDE) del SMC (figura 8) tiene la capacidad de detectar con un $90 \%$ de eficiencia las descargas NN, mientras que en otras redes esta capacidad se reduce a tan solo un $30 \%$, lo que no permite la aplicación del algoritmo (como demostraron Hering et al., 2018, en Suiza).

En el mapa de cobertura de la XDDE (figura 8) se observa la zona del Pirineo y extremo del nordeste del país con una menor de capacidad de detección. La zona con una mejor visión es la zona central de Cataluña donde el método de detección de los distintos sensores trabaja mejor.

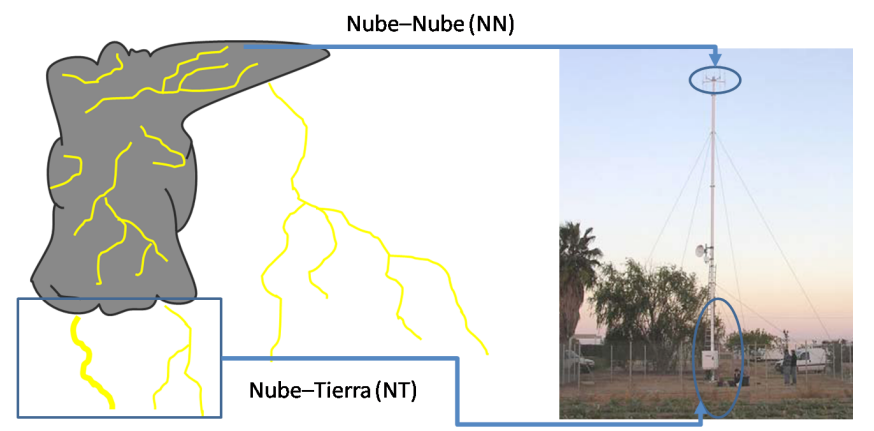

Figura 7. Sensor de Amposta de la XDDE.

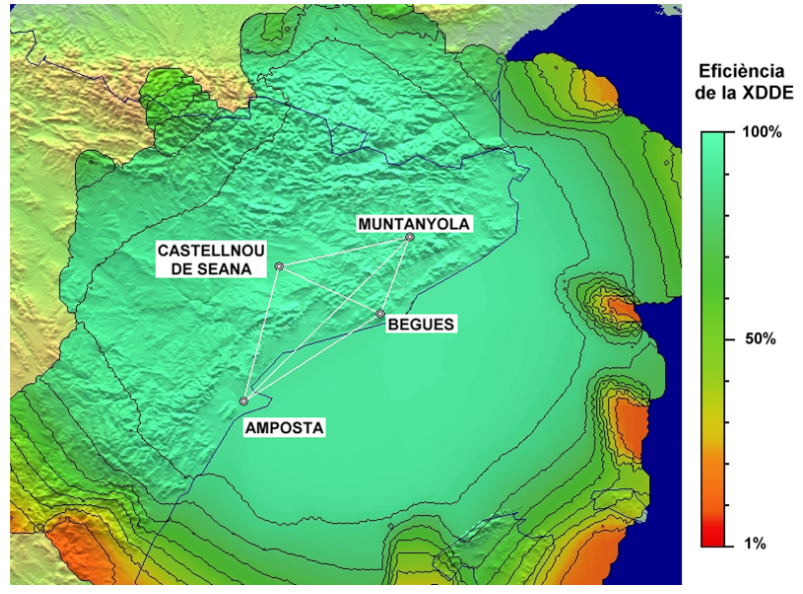

Figura 8. Mapa de cobertura de la XDDE en Cataluña.

En la fase inicial se analizó cómo respondía el F17 delante de los episodios de tiempo severo registrados en Cataluña durante el periodo 2006-2013. Se obtuvieron resultados prometedores con un porcentaje correcto (PC) de un $73 \%$ y tan solo un $10 \%$ de falsas alarmas (FA). Una característica importante del LJ es el lead time (LT), el cual calcula la distancia de tiempo entre que se detecta la alerta y observamos el fenómeno. La media de ese parámetro durante el periodo analizado se movió entre los 30 y 60 minutos.

En la figura 9 se observa la distribución del lead time, es decir, el nombre de alertas previas y posteriores al registro de tiempo severo. En ese análisis se tuvieron en cuenta todas las alertas. Ese aspecto es importante porque hay alertas que saltaron previas al registro de tiempo severo (figura 9 , alertas numeradas como 1 y 2 ) y posteriormente la alerta se activó de nuevo (figura 9, alerta número 3). Todas ellas han sido consideradas en ese gráfico, y por ese motivo el nombre de alertas posteriores al tiempo severo es numeroso. 


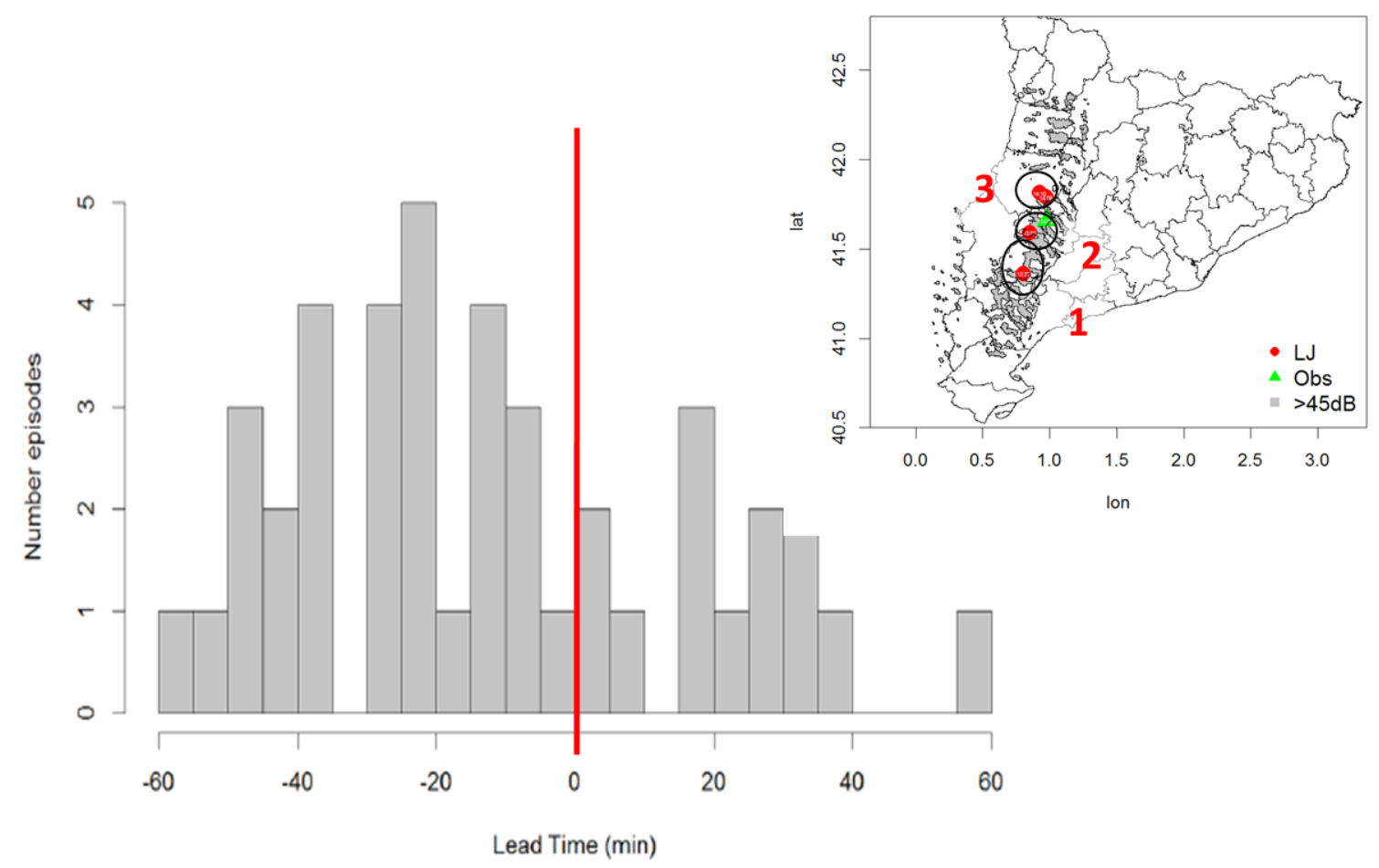

Figura 9. (Izquierda) Lead time calculado entre los registros de las alertas y las observaciones de tiempo severo registradas durante 2016. (Derecha) Ejemplo de episodio con varias alertas (marcadas con 1, 2 y 3 ) y un solo registro (indicado con un triángulo).

Los buenos resultados obtenidos durante este análisis previo permitieron que en 2016, l'Equip de Predicció i Vigilància del SMC (EPV-SMC) incorporase el LJ como herramienta preoperativa para detectar tiempo severo, y en 2017 la incorporó operativamente. Ese mismo año se continuó investigando sobre el mismo LJ y se incorporó el parámetro de la multiplicidad en el algoritmo. La multiplicidad de un relámpago es cuando se tiene en cuenta el máximo de nodos eléctricos que se han detectado en un determinado espacio y tiempo. Estos se considera que forman parte del mismo relámpago (figura 10).
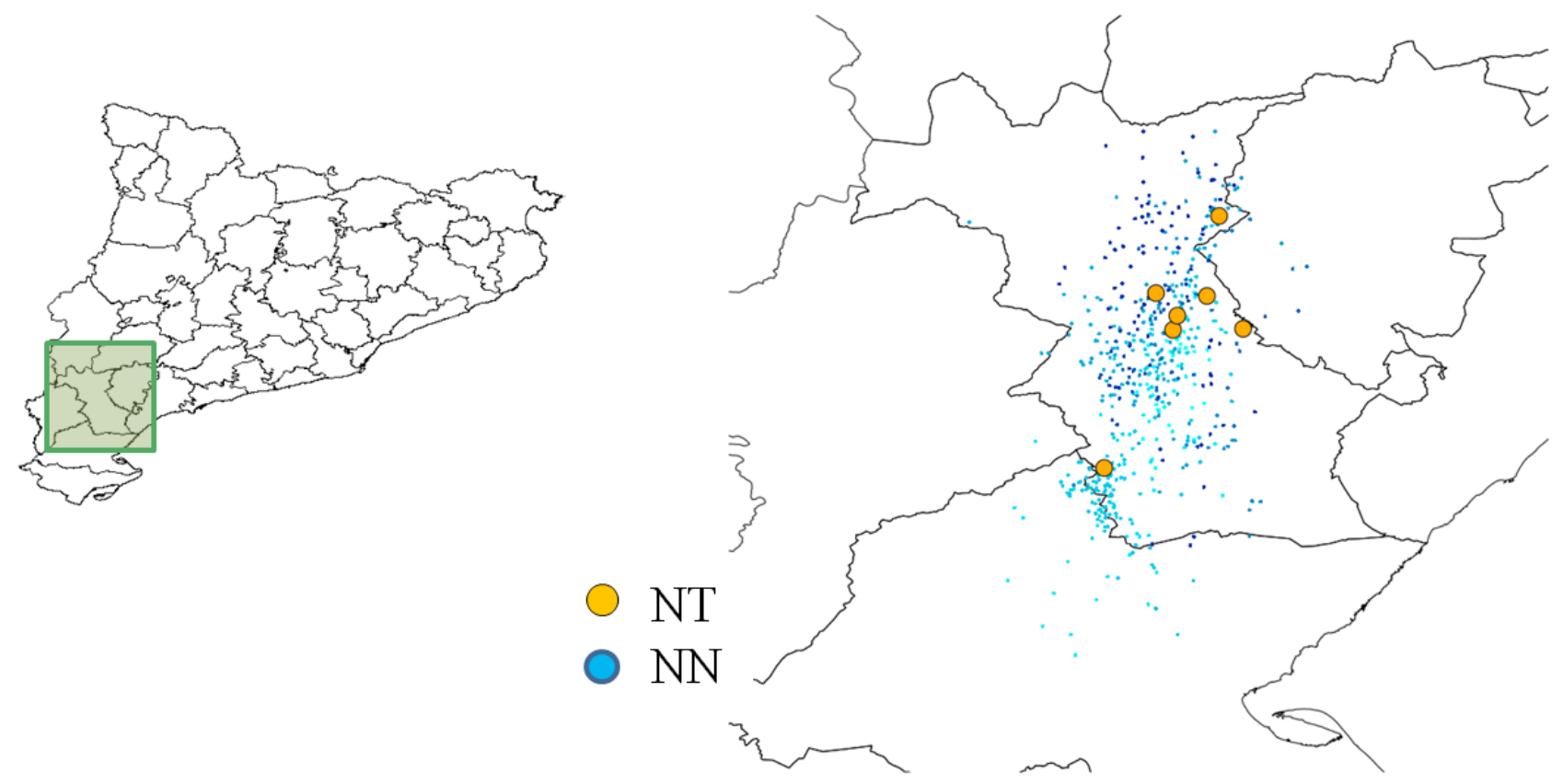

Figura 10. Ejemplo de relámpago considerando la multiplicidad.

Los relámpagos NN son representados en puntos azules y los NT en color naranja. 
En el análisis del comportamiento de la multiplicidad en el LJ se obtuvieron resultados también prometedores, con un aumento del LT y del porcentaje correcto pero, a la vez, se incrementaron ligeramente el número de falsas alarmas. La incorporación de este parámetro permitió detectar nuevos fenómenos, los cuales no solo están asociados a tiempo severo, sino también a granizo $<2 \mathrm{~cm}$, o bien a lluvias torrenciales.

Estos nuevos resultados permitieron hacer una segunda versión del LJ y trabajar con las dos en el EPV-SMC. De este modo, actualmente en el EPV-SMC se trabaja operativamente con el LJ con multiplicidad (LJM) y con el LJ sin multiplicidad (LJwoM), nombrados como LJ N1 y LJ N2, respectivamente.

En la figura 11 se muestra un ejemplo de cómo trabajan los dos tipos de LJ en un determinado episodio. El 22/05/2016 un núcleo tempestuoso cruzó desde Huesca (figura 11, 1) hacia el sur del Pla de Lleida (figura 11,2) hasta llegar al Prelitoral de Tarragona (figura 11, 3). En Huesca se activaron tres LJwoM y entre 20 y 50 minutos más tarde se registró granizo de tamaño pequeño al sur del Segrià (figura 11,4) y sur de las Garrigues (figura 11, 5). Seguidamente, saltó el LJM y LJwo y con un LT de entre 20 y 40 minutos se registró un reventón en la Conca de Barberà (figura 11,6).

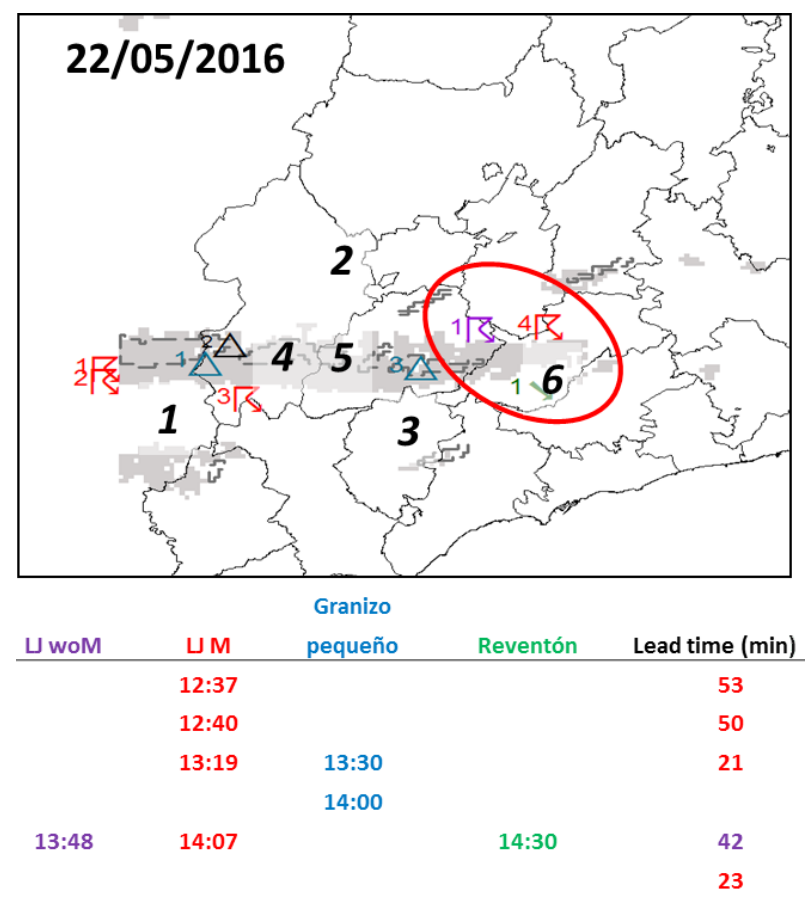

Figura 11. Comparación del LJ sin multiplicidad y con multiplicidad. Caso de estudio del 22/05/2016.
Durante la temporada 2017, el LT, teniendo en cuenta la multiplicidad, se movió alrededor de los 49 minutos con algunos registros con un LT mayor, superior a 1 hora. El porcentaje correcto fue de $81 \%$ y un $22 \%$ de falsas alarmas.

Con el fin de validar esta herramienta, las observaciones por parte de la población han sido esenciales. Desafortunadamente, a lo largo de este periodo se ha detectado una notable ausencia de estas en ciertos episodios, sobre todo en situaciones en que la tormenta se produjo durante la noche, o bien cuando ha afectado a zonas despobladas o con poca densidad de población como sucede en áreas de montaña (Cintineo et al., 2012).

Para incrementar ese vacío de observaciones, en el año 2017 se creó, desde el SMC, la campaña «Plega/Caça la Pedra». La campaña se preparó a nivel externo con un convenio con la diputación de Lleida y Girona, la Associació de Defensa del Vegetal Terres de Ponent (ADV Terres de Ponent) y la Universidad de León. A nivel interno se prepararon distintas redes sociales con Twitter, Facebook o Instagram con el identificativo \#meteocapedra y un número de whatsapp (667051592). Finalmente se gestionó un gestor de fotografías para unir todas la fotos y vídeos en un mismo portal. Además, cuando el EPV-SMC pronostica una posible situación de granizo en las comarcas de Girona o Lleida contactan con una agencia publicitaria, la cual difunde publicidad sobre la existencia de la campaña y la utilidad e importancia de las observaciones con el fin que la población tome consciencia de su existencia.

Durante ese primer año de campaña, el número de registros debido a esa representó un $44 \%$ del total de las observaciones, aproximadamente la mitad del total de las observaciones, a pesar de ser una temporada con verano anómalo térmicamente (figura 13).

En el mes de junio se registraron temperaturas máximas extremadamente altas, muy superiores a la media climática. En cambio, en julio y agosto, no hubo verano ya que son los meses más cálidos en Cataluña y, en cambio, se registraron temperaturas más bajas respecto a las del mes de junio, aunque sí que las noches fueron tropicales debido a la elevada humedad, sobre todo en las zonas costeras. Esa variación en el registro 


\section{A nivell externo:}

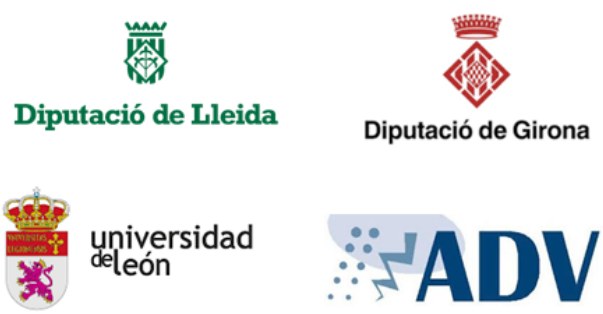

\section{A nivell interno:}
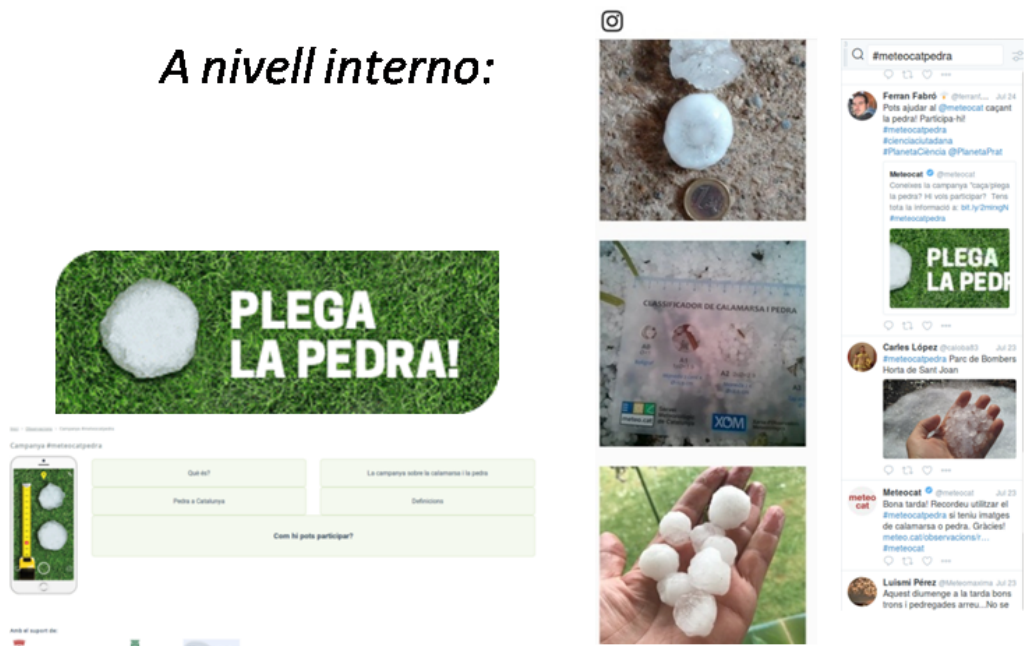

Figura 12. Preparación de la campaña Plega/caça la pedra.

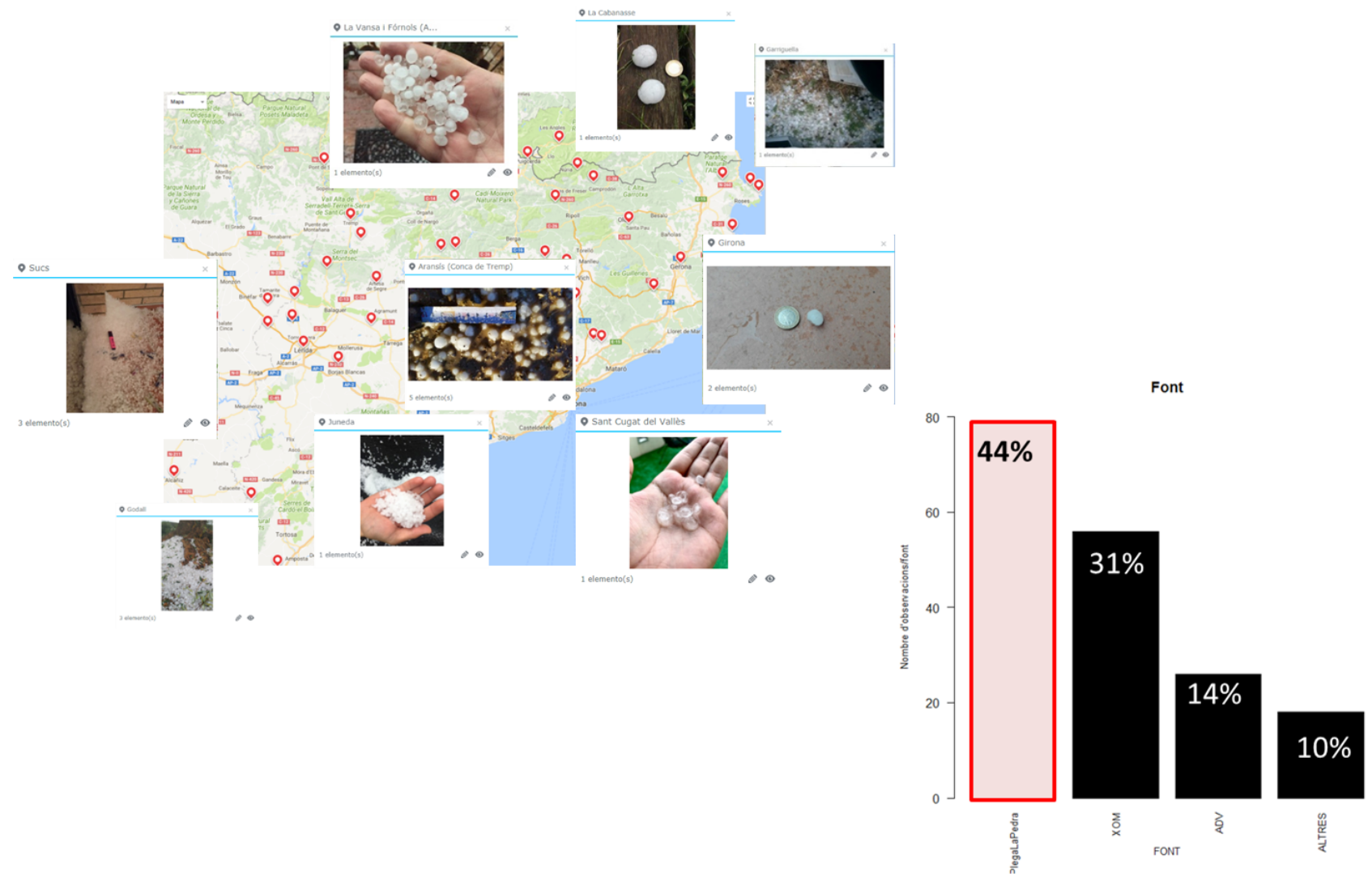

Figura 13. Valoración de los primeros resultados de la campaña.

de las temperaturas máximas anuales modificó la distribución mensual del número de alertas registradas durante ese mismo año, con un máximo en el mes de junio coincidiendo con el mes más cálido. Esa relación refleja el origen del tipo de tormentas que desencadenan un LJ (figura 14).

Eses máximos también se pueden encontrar en la distribución horaria con unos máximos al centro del día debido a la presencia de la convección como consecuencia de las altas temperaturas. Además, también se pueden observar algunos registros fuera de ese tramo horario debido a que la convección se mantiene durante unas largas horas o bien a la presencia de una situación inestable que favorece el desarrollo de las nubes durante la madrugada o a primeras horas de la mañana (no mostrado). 


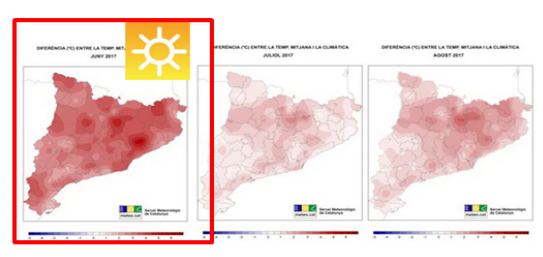

Observaciones

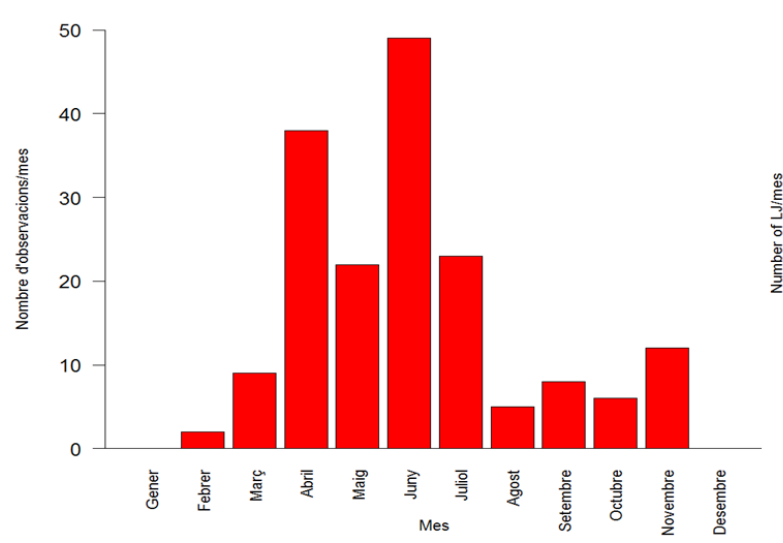

LJ alerta

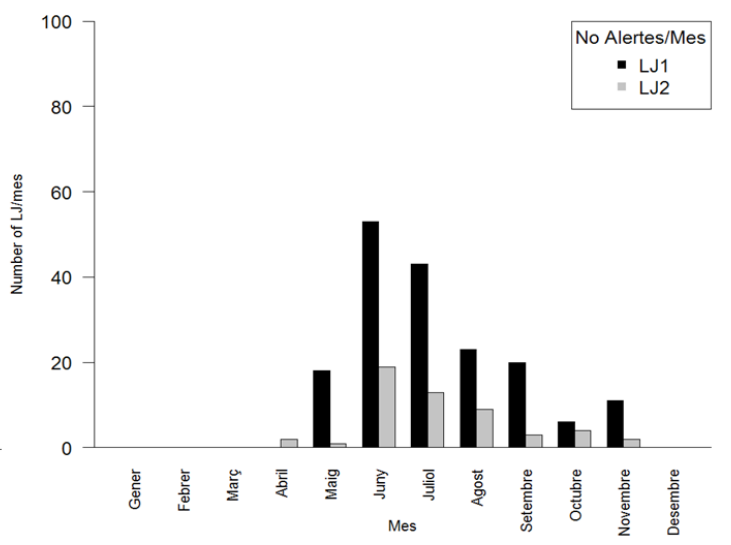

Figura 14. Distribución mensual de las alertas detectadas en Cataluña durante el año 2017 y de las observaciones de granizo registradas en eses mismo periodo.

Referente a la distribución espacial de los LJ y observaciones registradas durante ese mismo año, se observa un mayor nombre de alertas en la zona del Pirineu y, sobretodo del Prepirineu. Algunas de esas alertas también han sido detectadas en puntos del Prelitoral e interior de las comarcas del Pla de Lleida (figura 15). Sin embargo, los registros se pueden producir en zonas cercanos a las alertas o, por el contrario, a ciertas distancias, dependiendo del recorrido y velocidad de la tormenta. Es importante mencionar que donde hay alertas no es donde se produce el tiempo severo, ya que los núcleos convectivos que desencadenan un LJ tienden a moverse, de aquí esa diferencia espacial entre ambas distribuciones.

\section{LJ Alertas}

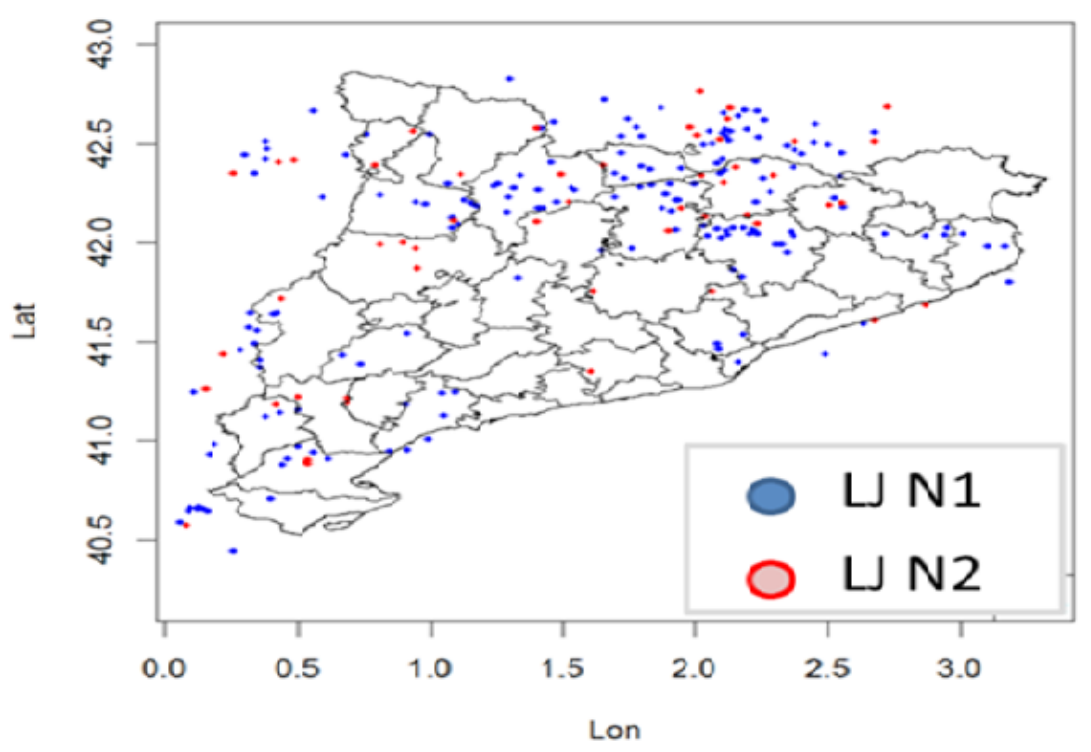

Figura 15.

Distribución territorial de las alertas detectadas en Cataluña durante el año 2017. 


\section{TRABAJO FUTURO INMEDIATO}

Justo antes de empezar la campaña de granizo de 2018 se incorporó un nuevo parámetro para mejorar la predicción de tiempo severo. Esa mejora tomó en cuenta el algoritmo del LJ combinado con la probabilidad de la trayectoria futura de la tormenta extrapolada por las imágenes radar, conocido como tracking radar (Rigo y Llasat, 2004).

El tracking radar permite conocer el movimiento de la tormenta en las próximas 2 horas después que el LJ haya sido activado. Los colores del producto indican la probabilidad de que la tormenta se desplace a un determinado punto durante las próximas 2 horas (figura 16, a). De ese modo, a partir del LJ podemos conocer si el núcleo convectivo puede ir asociado a tiempo severo y a partir del tracking radar, en qué lugar se puede registrar.

Ese conjunto de información permitirá al SMC realizar avisos de predicción de tiempo severo a corto plazo. Ese tipo de aviso trabajará de manera complementaria con los otros tipos de aviso que se realizan desde el SMC para Protección Civil, quién se comunica con los distintos ayuntamientos de Cataluña para advertir de ciertos fenómenos meteorológicos (figura 16).

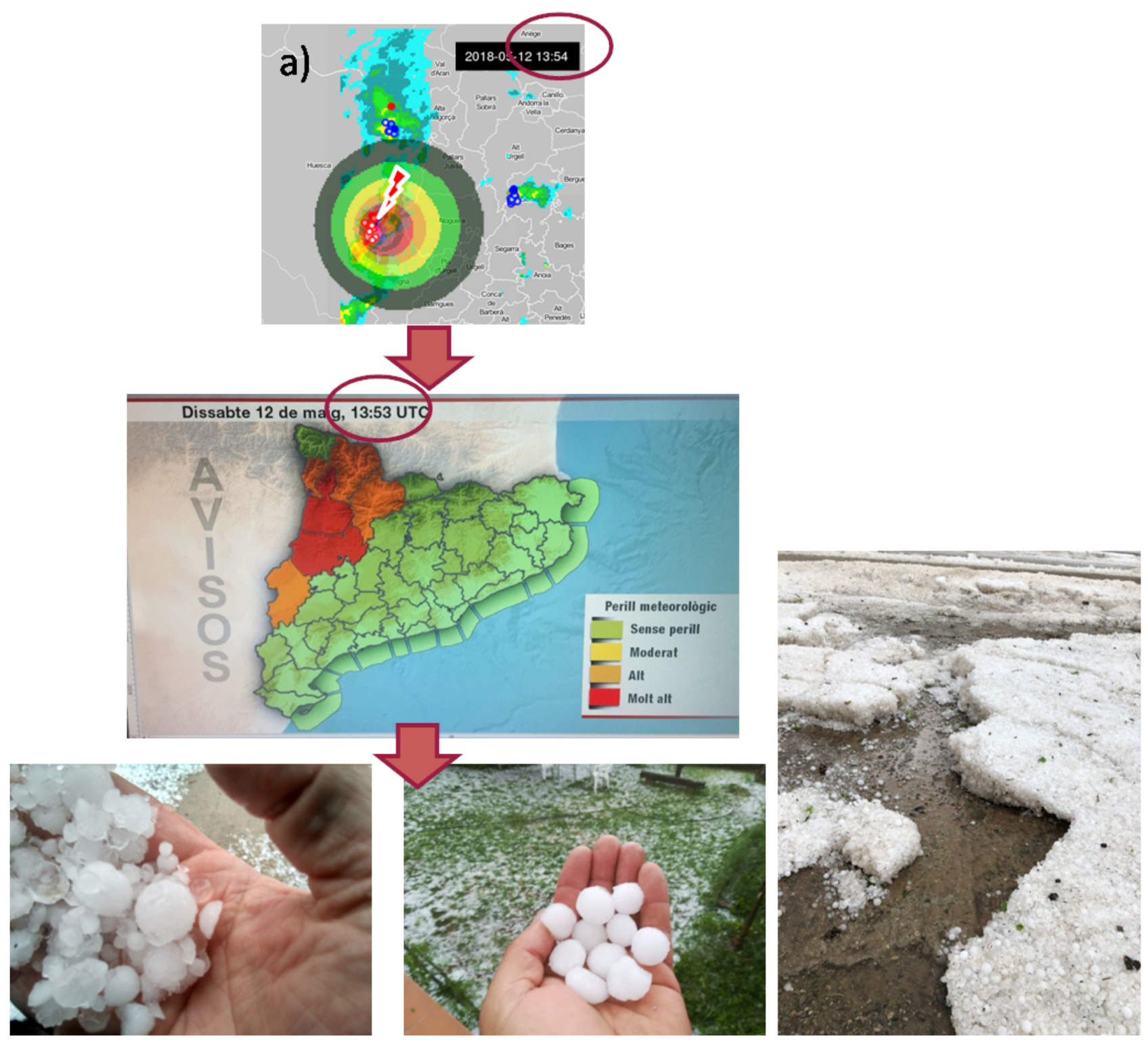

Figura 16. Funcionamiento de los futuros avisos de tiempo severo a corto plazo. 


\section{CONCLUSIONES}

El Servei Meterològic de Catalunya pretende poner en operativa una herramienta de avisos de tiempo severo en tormentas durante la campaña 2019. Estas alertas se enviarán a Protección Civil de Cataluña, ente responsable de realizar los avisos a la población catalana. Actualmente, aparte de los avisos de predicción, los únicos avisos a corto plazo que se generan se producen basándose en observaciones en superficie, mientras que estas alertas se producirán con una antelación de entre media y dos horas. Este tiempo de antelación se ha determinado a partir de las diferentes campañas que se han ido realizando: episodios históricos, puesta en preoperativa y operativa a nivel interno dentro del SMC.

La herramienta analiza los datos de descargas eléctricas dentro de cada tormenta y compara los valores actuales con el periodo previo, buscándose incrementos súbitos de la actividad eléctrica. Estos incrementos, que es lo que se conoce como Lightning Jumps, se deben a la mayor separación de las cargas dentro de las nubes, asociada con una fuerte corriente vertical ascendente, superior a la de las tormentas ordinarias. Este fenómeno es precursor del tiempo severo en superficie. Cuando se detecta uno de estos incrementos súbitos se genera una alerta en forma de correo electrónico, que se envía al Equipo de Predicción y Vigilancia. El predictor o grupo de predictores debe decidir, a partir de las características de la tormenta y la predicción del movimiento futuro más probable, qué comarca o comarcas se deben avisar, generando un mapa para las dos horas futuras. Este mapa es el que se va a enviar durante la campaña de 2019 a Protección Civil, para poder avisar a la población con un cierto margen de antelación, pudiendo gestionar de forma más eficiente situaciones que pueden resultar muy complejas, por el número de daños y afectaciones.

Gracias a la campaña Plega/Caça la Pedra se ha conseguido mejorar el registro de observaciones en superficie, lo que ha permitido realizar una buena validación de la alerta en los diferentes episodios que han ocurrido durante 2017 y 2018. Los índices muestran valores de probabilidad de detección de aproximadamente un $80 \%$ de los casos, con un $20 \%$ de falsas alarmas. Estos valores son realmente prometedores y pueden ayudar al predictor, al gestor de protección civil y al ciudadano a gestionar de forma más eficiente episodios meteorológicos de tiempo severo. En cualquier caso, el objetivo de los técnicos del SMC es seguir investigando y mejorando la herramienta y sus prestaciones en campañas posteriores.

\section{AGRADECIMIENTOS}

Queremos agradecer a la Organización del VI Simposio de Predicción de AEMET por invitarnos a mostrar nuestro trabajo. Además, los autores damos las gracias a nuestros compañeros, por las ideas y propuestas de mejora.

\section{REFERENCIAS}

Cintineo, J. L., Smith, T. M., Lakshmanan, V., Brooks, H. E. y Ortega, K. L., 2012. An objective highresolution hail climatology of the contiguous United States. Weather and Forecasting, 27 (5), 1235-1248.

FARnell, C., Rigo, T. y Pineda, N., 2017. Lightning jump as a nowcast predictor: Application to severe weather events in Catalonia. Atmospheric Research, 183: 130-141.

Gatuin, P. N. y Goodman, S. J., 2010. A total lightning trending algorithm to identify severe thunderstorms. Journal of atmospheric and oceanic technology, 27 (1), 3-22.

Hering, A., Nisi, L., Hamann, U. y Germann, U., 2018. The nowcasting potential of lightning-jumps in convective cells tracked by radar in complex orography. $10^{\text {th }}$ European Conference on Radar in Meteorology and Hydrology (ERAD 2018): 1-6 July 2018, Ede-Wageningen, The Netherlands. 
Rigo, T. y LlasAt, M.C., 2004. A methodology for the classification of convective structures using meteorological radar: Application to heavy rainfall events on the Mediterranean coast of the Iberian Peninsula. Natural Hazards and Earth System Science, 4 (1), 59-68.

Schultz, C. J., Petersen, W. A. y Carey, L. D., 2009. Preliminary development and evaluation of lightning jump algorithms for the real-time detection of severe weather. Journal of Applied Meteorology and Climatology, 48(12): 2543-2563.

Williams, E., Boldi, B., Matlin, A., Weber, M., Hodanish, S., Sharp, D. y Buechler, D., 1999. The behavior of total lightning activity in severe Florida thunderstorms. Atmospheric Research, 51(3-4), 245-265.

WiLliams, E. R., 2001. The electrification of severe storms. Severe Convective Storms. American Meteorological Society, Boston, MA. 527-561. 